\title{
Effect of CdS/Mg-Doped CdSe Cosensitized Photoanode on Quantum Dot Solar Cells
}

\author{
Yingxiang Guan, Xiaoping Zou, and Sheng He \\ Research Center for Sensor Technology, Beijing Key Laboratory for Sensor, \\ Ministry of Education Key Laboratory for Modern Measurement and Control Technology, School of Applied Sciences, \\ and School of Information \& Communication Engineering, Beijing Information Science and Technology University, \\ Jianxiangqiao Campus, Beijing 100101, China
}

Correspondence should be addressed to Xiaoping Zou; xpzou2005@gmail.com

Received 31 May 2014; Accepted 13 August 2014

Academic Editor: Yongfeng Li

Copyright (C) 2015 Yingxiang Guan et al. This is an open access article distributed under the Creative Commons Attribution License, which permits unrestricted use, distribution, and reproduction in any medium, provided the original work is properly cited.

\begin{abstract}
Quantum dots have emerged as a material platform for low-cost high-performance sensitized solar cells. And doping is an effective method to improve the performance of quantum dot sensitized solar cells (QDSSCs). Since Kwak et al. from South Korea proved the incorporation of $\mathrm{Mg}$ in the CdSe quantum dots (QDs) in 2007, the Mg-doped CdSe QDs have been thoroughly studied. Here we report a new attempt on CdS/Mg-doped CdSe quantum dot cosensitized solar cells (QDCSSC). We analyzed the performance of $\mathrm{CdS} / \mathrm{Mg}$-doped CdSe quantum dot cosensitized solar cells via discussing the different doping concentration of $\mathrm{Mg}$ and the different SILAR cycles of CdS. And we studied the mechanism of CdS/Mg-doped CdSe QDs in detail for the reason why the energy conversion efficiency had been promoted. It is a significant instruction on the development of Mg-doped CdSe quantum dot sensitized solar cells (QDSSCs).
\end{abstract}

\section{Introduction}

Recently, doping of semiconductor quantum dot has been largely developed. It provides a broad way to achieve lowcost high-performance optoelectronic devices. Lee and his colleagues reported on a $\mathrm{PbS}: \mathrm{Hg}$ QDSSC with high power conversion of $5.6 \%$ for the extremely high $J_{\mathrm{sc}}\left(30 \mathrm{~mA} / \mathrm{cm}^{2}\right)$ last year [1]. It has shown the great potential of QDSSCs. CdSe is a kind of sensitizer system and has gotten lots of research. Mg-doped CdSe is one kind of doping scheme. In 2007, Kwak et al. proved that Mg was doped into CdSe with $\mathrm{X}$-ray energy dispersive spectroscopy (EDS) and inductively coupled plasma mass spectrometry (ICPMS) [2]. And they adjusted the band-gap of CdSe nanocrystalline by doping CdSe with Mg which was blue shifted and the intensity of PL spectra of doped CdSe nanocrystalline was similar with that of undoped CdSe nanocrystalline, or even higher. Then they enhanced the ripening kinetics of Mg-doped CdSe nanocrystals because of the low activation energy for the volume diffusion [3]. In 2008, Wonjoo et al. prepared CdSe/Mg-doped
CdSe QDSSCs with chemical bath deposition (CBD) method [4]. It had a more broad range of spectral response in visible region. Thus, the short-circuit current was enhanced by $47 \%$, but the fill factor (FF) and the open circuit voltage did not change significantly compared with undoped CdSe QDSSCs. In 2010, Wang et al. from Qufu Normal University announced the first-principles on the electron structure and optical properties of Mg-doped CdSe system [5]. They calculated the electron structure and optical properties of wurtzite structure $\mathrm{Cd}_{1-x} \mathrm{Mg}_{x} \mathrm{Se}(x=0,0.125,0.250,0.375)$ by using first-principles ultrasoft pseudopotential plane wave method based on the density functional theory (DFT). The result showed that Se4p electrons fundamentally determined the top of valence band which was essentially the same, while both Se4s electrons and Cd5s electrons determined the bottom of conduction band which was moved to a higher energy region with the increasing $\mathrm{Mg}$ concentration, and the band-gap was also broadened. As a result, the peaks in the imaginary part of the dielectric function and the peak in the real part of the refractive index were blue shifted with the 
increasing Mg concentration. The CdS/CdSe system is one of the most studied systems. Lee et al. achieved an energy conversion efficiency of $4.22 \%$ by using a $\mathrm{TiO}_{2} / \mathrm{CdS} / \mathrm{CdSe} / \mathrm{ZnS}$ electrode structure in 2009 [6]. Because of the Fermi level alignment, a stepwise structure of band-edge levels was yielded in the cascade structure of $\mathrm{TiO}_{2} / \mathrm{CdS} / \mathrm{CdSe}$ electrode. And it profited the electron injection and hole recovery.

As we were enlightened by the previous research on doping [7-9] of our research group and the research on $\mathrm{Mg}$ doped CdSe and CdS/CdSe photoanode structure of others, we report a quantum dot cosensitized solar cell prepared by using successive ionic layer absorption and reaction (SILAR) method based on cosensitized CdS/Mg-doped CdSe QDs. (Mg-CdSe stands for Mg-doped CdSe.)

\section{Methods}

2.1. Device Fabrication. Firstly, with regard to $\mathrm{TiO}_{2}$ films fabrication, $\mathrm{TiO}_{2}$ films were printed on the cleaned FTO glass which was treated by a $0.4 \mathrm{M} \mathrm{TiCl}_{4}$ solution and then annealed at $450^{\circ} \mathrm{C}$ for $30 \mathrm{~min}$ with screen printing method and then annealed at $450^{\circ} \mathrm{C}$ for $30 \mathrm{~min}$. The thickness of $\mathrm{TiO}_{2}$ films was about $8.5 \mu \mathrm{m}$ and the working area was $0.5 \times 0.5 \mathrm{~cm}^{2}$. Secondly, in photoanode fabrication, the $\mathrm{TiO}_{2}$ films were dipped into a $\mathrm{Cd}\left(\mathrm{NO}_{3}\right)_{2}$ ethanol solution $(0.1 \mathrm{M})$ for $5 \mathrm{~min}$ and then rinsed with ethanol. After being dried with nitrogen they were dipped into a $\mathrm{Na}_{2} \mathrm{~S}$ methanol solution $(0.1 \mathrm{M})$ for $5 \mathrm{~min}$ and then rinsed with methanol. The two steps were termed as one SILAR cycle. It was similar to the deposition of $\mathrm{Mg}$-CdSe QDs; the cation solution was prepared by adding the $\mathrm{MgCl}_{2} \cdot 6 \mathrm{H}_{2} \mathrm{O}$ into preceding $\mathrm{Cd}^{2+}$ solution with a settled molar concentration ratio. The anion solution $\left(\mathrm{Na}_{2} \mathrm{SeSO}_{3}\right)$ was prepared by refluxing $\mathrm{Se}$ $(0.06 \mathrm{M})$ into a $\mathrm{Na}_{2} \mathrm{SO}_{3}$ aqueous solution $(0.12 \mathrm{M})$ at $70^{\circ} \mathrm{C}$ for $7 \mathrm{~h}$. But there were longer time (ca. $30 \mathrm{~min}$ ) and higher temperature $\left(50^{\circ} \mathrm{C}\right)$ for dipping them into anion solution. Thirdly, in counter electrode fabrication, Pt counter electrode was prepared by thermal decomposition of chloroplatinic acid; the method is as follows: $0.053 \mathrm{~g}$ chloroplatinic acid was dissolved in $10 \mathrm{~mL}$ isopropanol to fabricate platinum paste. Then, the Pt counter electrode could be obtained by annealing the FTO glass which was coated with the platinum paste in Muffle furnace at $450^{\circ} \mathrm{C}$ for $30 \mathrm{~min}$. Fourthly in electrolyte preparation,polysulfide electrolyte was prepared by dissolving $1 \mathrm{M} \mathrm{Na}_{2} \mathrm{~S}$ and $1 \mathrm{M} \mathrm{S}$ in deionized water. Finally, with regard to cells packaging, the prepared photoanode was put on laboratory bench (the coated side facing up). Next a hollow rectangle spacer with the thickness of $60 \mu \mathrm{m}$ was placed around the photoanode. Then the prepared Pt counter electrode (the conductive side facing down) was put on the photoanode. Then the electrolyte was injected into the cell from the gap between photoanode and counter electrode followed by griping the cell with clips. (Finished cell should be placed under dark for $40 \mathrm{~min}$ before testing.)

2.2. Material Characterization. Scanning electron microscopy (SEM) was used to observe the surface of the films. SEM was performed with a S- 4300 of Technical Institute of Physics

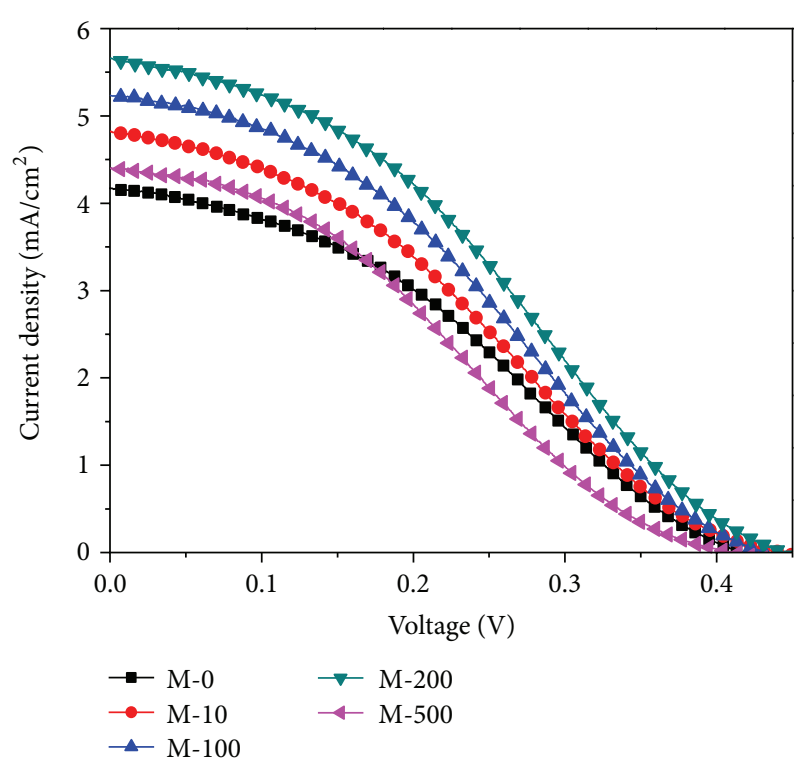

FIGURE 1: The J-V curves of the cells made by sample solution of M- 0 , M-10, M-100, M-200, and M-500.

and Chemistry, CAS. Energy dispersive X-ray spectroscopy (EDS) was employed with S-4300 equipped with a highperformance energy dispersive X-ray spectroscopy (EDS). Transmission electron microscopy (TEM) was measured with Tecnai G2 F20 S-TWIN at $200 \mathrm{KV}$. X-ray diffraction (XRD) was performed with Bruker D8 focus. Absorption spectra were measured with a Varian Cary 5000 UV-Vis spectrophotometer. Inductively coupled plasma optical emission spectroscopy (ICP-IOS) analysis was performed with a Thermo Fisher IRIS Intrepid II XSP.

2.3. Device Characterization. J-V curves were obtained by using J-V test system which consisted of solar simulator $\left(100 \mathrm{~mW} / \mathrm{cm}^{2}\right.$ AM 1.5), irradiance meter, electrochemical workstation (Linear Scan Voltammetry mode), test software, and so on (Figure 2). IPCE measurements were obtained with a IPCE measurement tool $\left(0.3-0.8 \mathrm{~mW} / \mathrm{cm}^{2}, 350-800 \mathrm{~nm}\right)$ developed by Institute of Physics, CAS, through DC method. EIS was measured with Princeton Applied Research, V3-400 electrochemical workstation equipped with electrochemical impedance test system. The bias was $-0.5 \mathrm{~V}$, the scanning frequency was from $0.1 \mathrm{~Hz}$ to $500 \mathrm{KHz}$, and the amplitude modulation was $20 \mathrm{mV}$.

\section{Results and Discussions}

3.1. Effect of Different Doping Concentration of $\mathrm{Mg}$ on the Performance of CdS/Mg-CdSe Quantum Dots Cosensitized Solar Cells. Because of the different doping concentration of $\mathrm{Mg}$, some doped cells performed better than undoped cells, while some did not (Figure 1). The short-circuit current, fill factor, and efficiency of the cells increased first and then reduced (Table 1) with the decrease of doping concentration (from 1:10 to 1:500). Mg exited in CdSe QDS as dopant, 


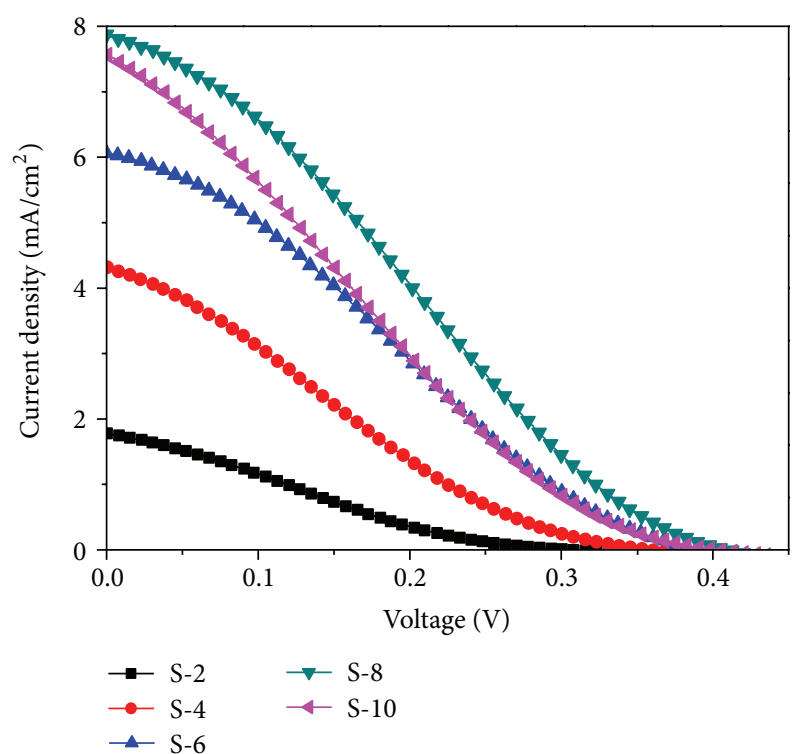

Figure 2: The J-V curves of samples of S-2, S-4, S-6, S-8, and S-10.

TABLE 1: The performance parameters of cells made by sample solution of M-0, M-10, M-100, M-200, and M-500.

\begin{tabular}{lcccc}
\hline Samples & $J_{\text {sc }}\left(\mathrm{mA} / \mathrm{cm}^{2}\right)$ & $V_{\mathrm{OC}}(\mathrm{V})$ & $\mathrm{FF}$ & $\eta(\%)$ \\
\hline M-0 & 4.17 & 0.42 & 0.35 & 0.61 \\
M-10 & 4.82 & 0.44 & 0.32 & 0.68 \\
M-100 & 5.24 & 0.43 & 0.34 & 0.77 \\
M-200 & 5.66 & 0.44 & 0.34 & 0.85 \\
M-500 & 4.40 & 0.41 & 0.32 & 0.57 \\
\hline
\end{tabular}

M-0 stands for that the doping concentration of Mg is 0 ; similarly, M-10, M$100, \mathrm{M}-200$, and $\mathrm{M}-500$, respectively, stand for the doping concentration of $\mathrm{Mg}(\mathrm{Mg}: \mathrm{Cd})$ of $1: 10,1: 100,1: 200$, and 1:500. Each sample was deposited with 4 SILAR cycles of CdS followed by 4 SILAR cycles of Mg-CdSe.

which not only enhanced the short-circuit current density, but also decreased the short-circuit current density as it became the recombination center of electrons and holes. When the concentration of $\mathrm{Mg}$ was 1:200, we got the optimal result between the two factors. And because of the recombination centers introduced by dopant $\mathrm{Mg}$, the opencircuit voltage did not change significantly.

\subsection{Effect of Different SILAR Cycles of CdS on the Performance} of CdS/Mg-CdSe Quantum Dot Cosensitized Solar Cells. We studied the effect of different SILAR cycles on the performance of CdS/Mg-CdSe quantum dot cosensitized solar cells after we got the best doping ratio $(\mathrm{Mg}: \mathrm{Cd}=1: 200)$. The short-circuit current and open-circuit voltage (Table 2) keep increasing until the SILAR cycles of CdS are 8 and get to the maximum value of $7.87 \mathrm{~mA} / \mathrm{cm}^{2}$ and $0.41 \mathrm{~V}$, respectively. However, the maximum efficiency of $0.84 \%$ was not further improved than previous experimental data. There might have been some problems in the preparation of $\mathrm{TiO}_{2}$ films or $\mathrm{Pt}$ counter electrode. But the optimization of SILAR cycles of CdS has been shown in this experiment.
TABLE 2: The performance parameters of samples of S-2, S-4, S-6, S-8, and S-10.

\begin{tabular}{lcccc}
\hline Samples & $J_{\text {sc }}\left(\mathrm{mA} / \mathrm{cm}^{2}\right)$ & $V_{\mathrm{OC}}(\mathrm{V})$ & $\mathrm{FF}$ & $\eta(\%)$ \\
\hline S-2 & 1.79 & 0.31 & 0.22 & 0.12 \\
S-4 & 4.31 & 0.36 & 0.22 & 0.34 \\
S-6 & 6.06 & 0.39 & 0.26 & 0.61 \\
S-8 & 7.87 & 0.41 & 0.26 & 0.84 \\
S-10 & 7.55 & 0.40 & 0.22 & 0.65 \\
\hline
\end{tabular}

S-2 means that the deposition cycles of CdS were 2. Similarly, S-4, S-6, S-8, and S-10 mean the deposition cycles of CdS were $4,6,8$, and 10, respectively. All the deposition cycles of Mg-CdSe were 4.

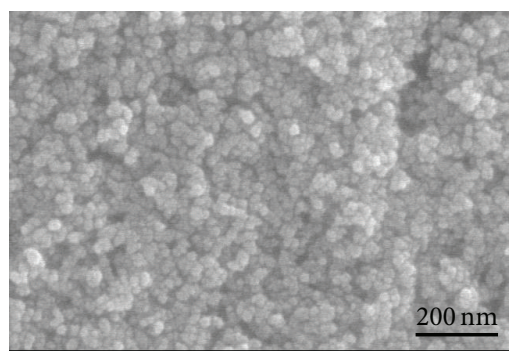

(a)

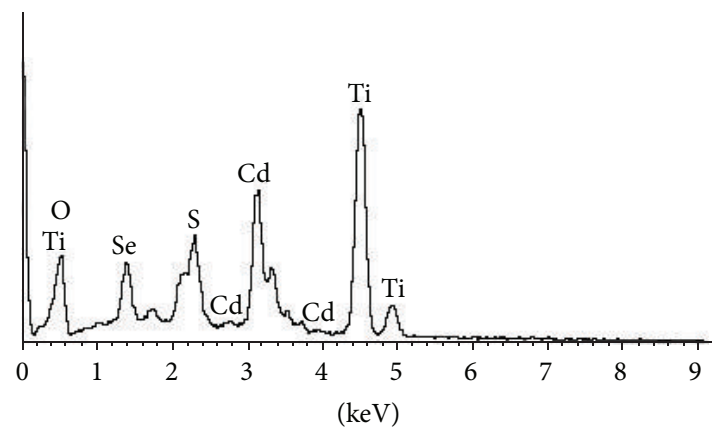

(b)

FIGURE 3: (a) The SEM image and (b) the EDS spectra of photoanode.

3.3. Analysis of $\mathrm{Mg}$-CdSe Effecting the Performance of CdS/CdSe Quantum Dot Cosensitized Solar Cells. We found that Mg-doped CdSe had a great enhancement on the performance of CdS/CdSe quantum dot cosensitized solar cells (Figure 1). Here we analyze the mechanism of $\mathrm{Mg}$ CdSe effecting the performance of CdS/CdSe quantum dot cosensitized solar cells specifically.

\subsubsection{The Material Characterization of CdS/Mg-CdSe Photo-} anode. As we can see from the scanning electron microscopy (SEM) image of photoanode (Figure 3(a)), the size of $\mathrm{TiO}_{2}$ is about $20 \mathrm{~nm}$. However, it is hard to find the quantum dots in the SEM image. So we used transmission electron microscopy (TEM) to characterize the quantum dots.

Furthermore, we could not find element $\mathrm{Mg}$ in the energy dispersive spectroscopy (EDS) spectra (Figure 3(b)) of photoanode because the weight of $\mathrm{MgCl}_{2} \cdot 6 \mathrm{H}_{2} \mathrm{O}$ was too little for just $0.0051 \mathrm{~g}$ to detect characteristic X-rays of 


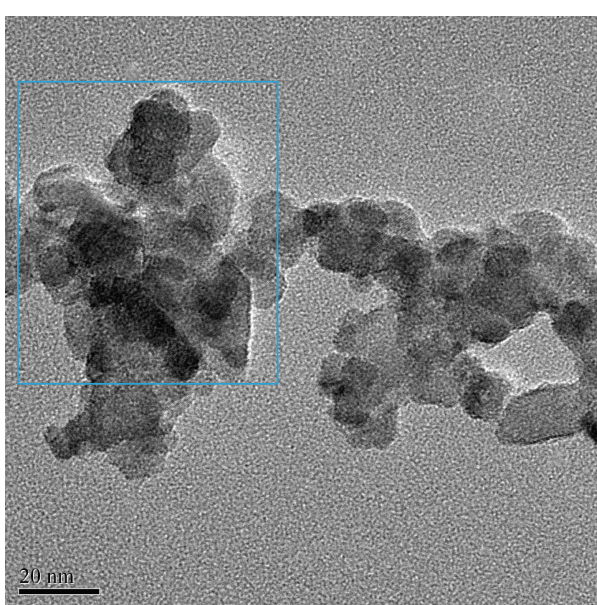

(a)

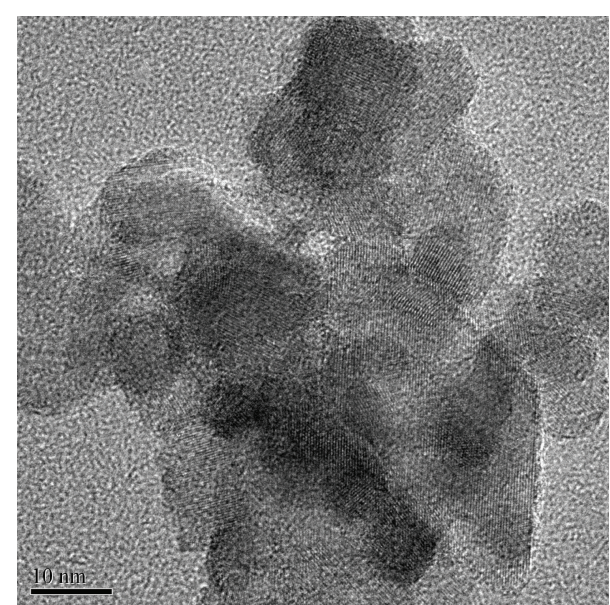

(b)

FIgURE 4: TEM images of (a) low magnification and (b) high magnification.

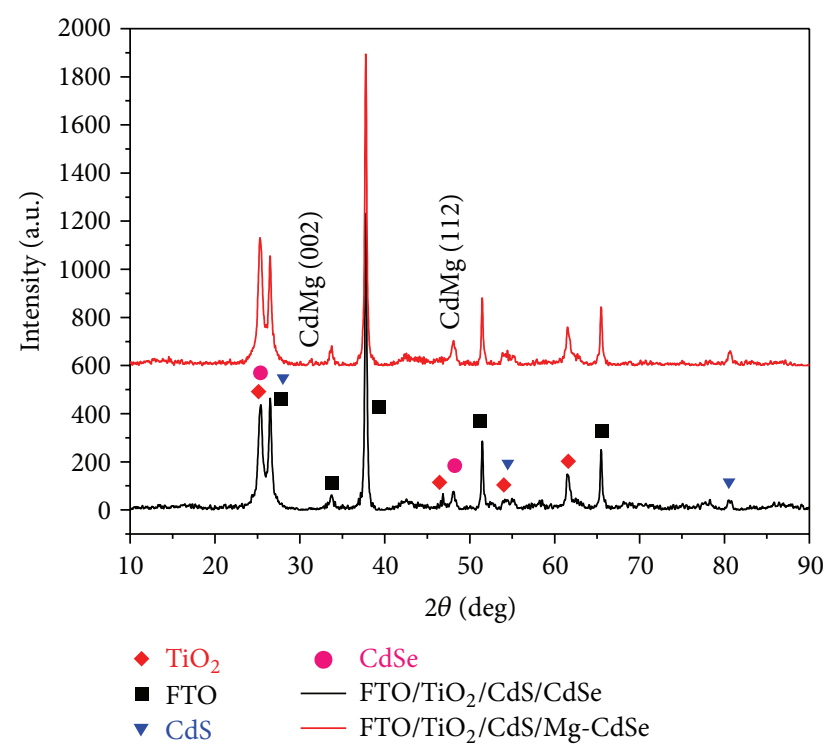

FIGURE 5: XRD pattern of CdS/Mg-doped CdSe photoanode.

element $\mathrm{Mg}$. So as to analyze element $\mathrm{Mg}$ qualitatively and quantitatively, we used inductively coupled plasma optical emission spectroscopy.

The size of nanoparticles is about 5-20 nm (Figure 4(a)). Furthermore, the smaller particles of Mg-doped QDs that were found, which are the size of $5 \mathrm{~nm}$, are on the surface of bigger particles of $\mathrm{TiO}_{2}$ (Figure $4(\mathrm{~b})$ ).

$\mathrm{XRD}$ results (Figure 5) show that the $\mathrm{CdS} / \mathrm{Mg}$-CdSe photoanode has a diffraction peak from impurity atoms of $\mathrm{Mg}$ except for diffraction peaks of $\mathrm{FTO}, \mathrm{TiO}_{2}, \mathrm{CdS}$, and $\mathrm{CdSe}$. Two peaks corresponding to lattice plane (002) and (112) of $\mathrm{CdMg}$ have been identified at $33.8^{\circ}$ and $48.1^{\circ}$, respectively. Particularly, the peak of CdSe at $48.1^{\circ}$ has been a little left shifted by $0.01^{\circ}$ (from $48.10739^{\circ}$ to $48.09740^{\circ}$ ) through lattice distortion caused by doping with $\mathrm{Mg}$ and it is very likely that the peak of $\mathrm{TiO}_{2}$ at $46.8^{\circ}$ has disappeared after being covered
TABLE 3: Quantitative analysis of ICP-OES.

\begin{tabular}{lccc}
\hline Sample & $\mathrm{Cd}(\mu \mathrm{g})$ & $\mathrm{Mg}(\mu \mathrm{g})$ & Molar ratio $(\mathrm{Mg}: \mathrm{Cd})$ \\
\hline Mg-CdSe & 25.51 & 0.0299 & $0.54 \%$ \\
\hline
\end{tabular}

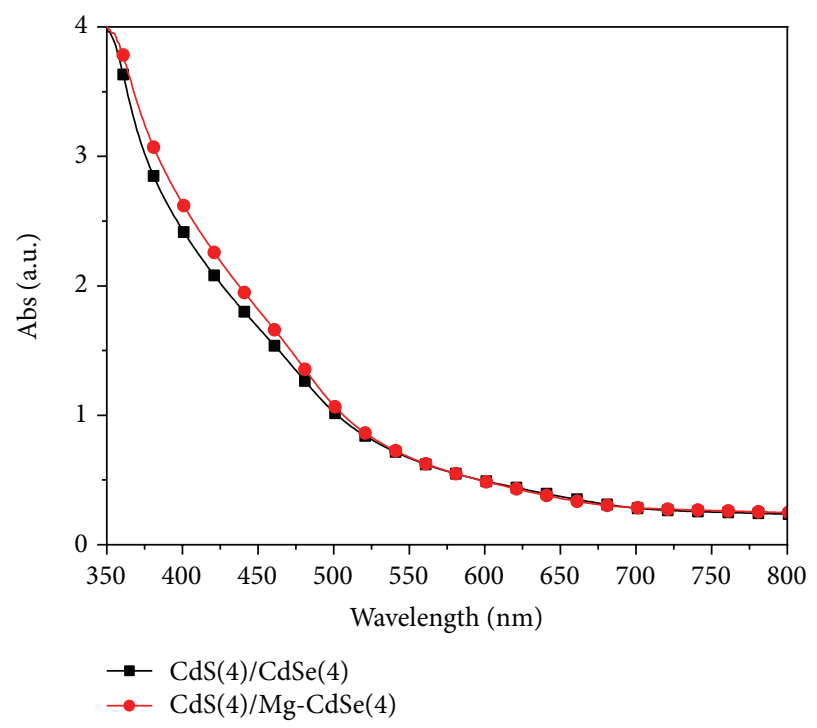

Figure 6: UV-Vis absorption spectroscopy of CdS(4)/Mg-CdSe(4) and $\mathrm{CdS}(4) / \mathrm{CdSe}(4)$.

with quantum dots. So the element $\mathrm{Mg}$ dose has doped inside photoanode.

In order to further determine if the element $\mathrm{Mg}$ has doped into CdSe QDs, we analyzed quantitatively with ICP-OES (Table 3).

The experimental doping concentration of $\mathrm{Mg}$ was $0.5 \%$ ( $\mathrm{Mg}: \mathrm{Cd}=1: 200)$. However, the molar ratio of $\mathrm{Mg}: \mathrm{Cd}$ was $0.54 \%$ actually. That was higher than the experimental data. It might be because the $\mathrm{Mg}$ ions reacted with Se ions more easily. 


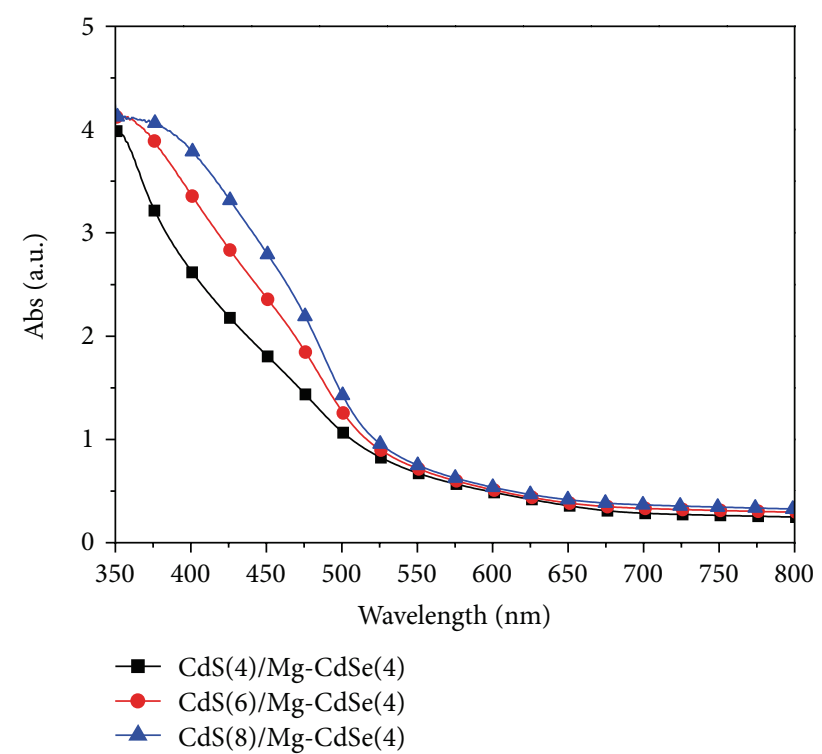

Figure 7: UV-Vis absorption spectroscopy of CdS/Mg-CdSe photoanode of different SILAR cycles.

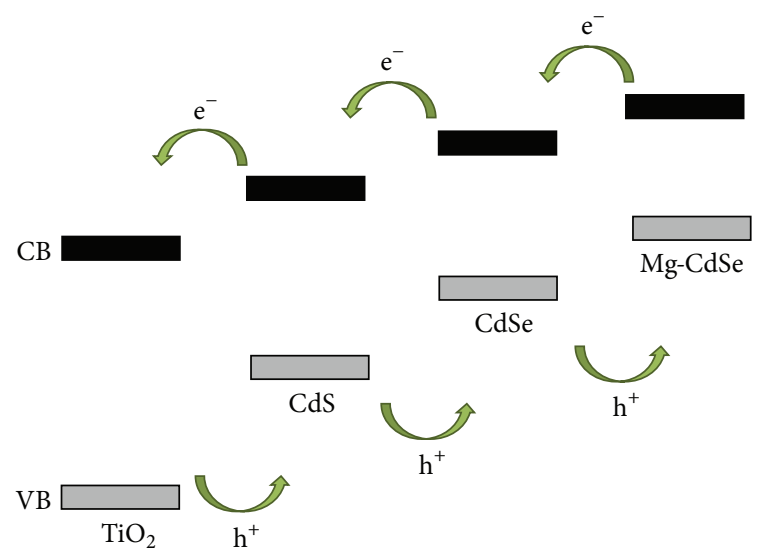

Figure 8: Energy level alignment by doping CdSe with Mg.

The comparison between absorption spectroscopy of $\mathrm{CdS}(4) / \mathrm{Mg}-\mathrm{CdSe}(4)$ and that of $\mathrm{CdS}(4) / \mathrm{CdSe}(4)$ in UV-Vis (Figure 6) shows that the absorption of Mg-doped photoanode has performed a little better than undoped photoanode in the wavelength ranging from $350 \mathrm{~nm}$ to $525 \mathrm{~nm}$ according to the enhancement of current concentration.

As the deposition cycles of CdS were not optimal, we measured the absorption spectroscopy of $\mathrm{CdS} / \mathrm{Mg}$-CdSe photoanode with different SILAR cycles (Figure 7). The absorption of photoanode has been improved with the increasing of SILAR cycles from 4 to 8 in the same wavelength range when the deposition cycles of $\mathrm{Mg}$-CdSe are 4, especially in the wavelength of $350-500 \mathrm{~nm}$.

According to the UV-Vis absorption spectroscopy, the band-gap of CdSe has been narrowed by doping with $\mathrm{Mg}$. Then we made a possible diagram (Figure 8 ) of the adjustment of Mg-CdSe energy level $[6,9]$. The conduction band

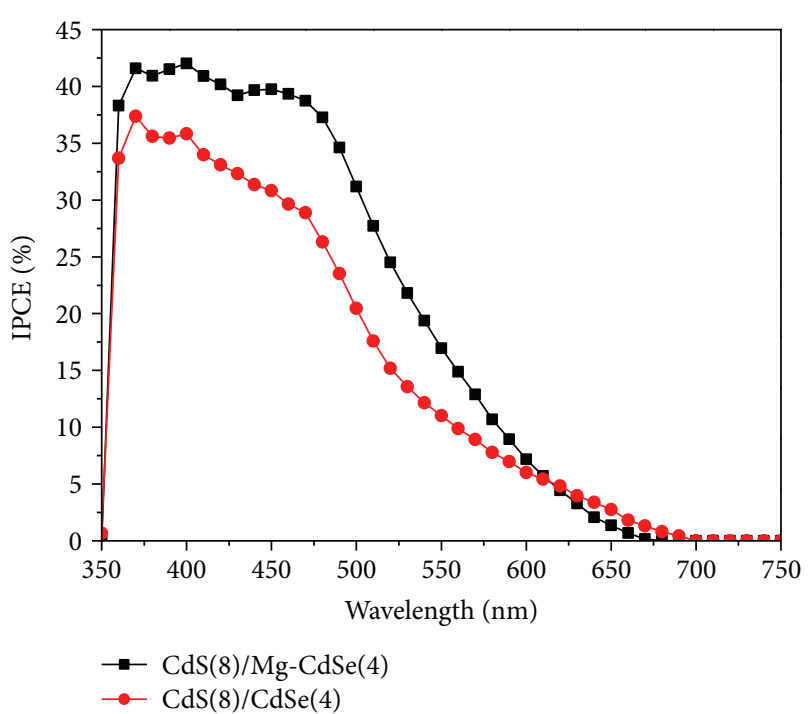

FIgURE 9: IPCE curves of cells made by the photoanode of $\mathrm{CdS}(8) / \mathrm{Mg}-\mathrm{CdSe}(4)$ and $\mathrm{CdS}(8) / \mathrm{CdSe}(4)$, respectively.

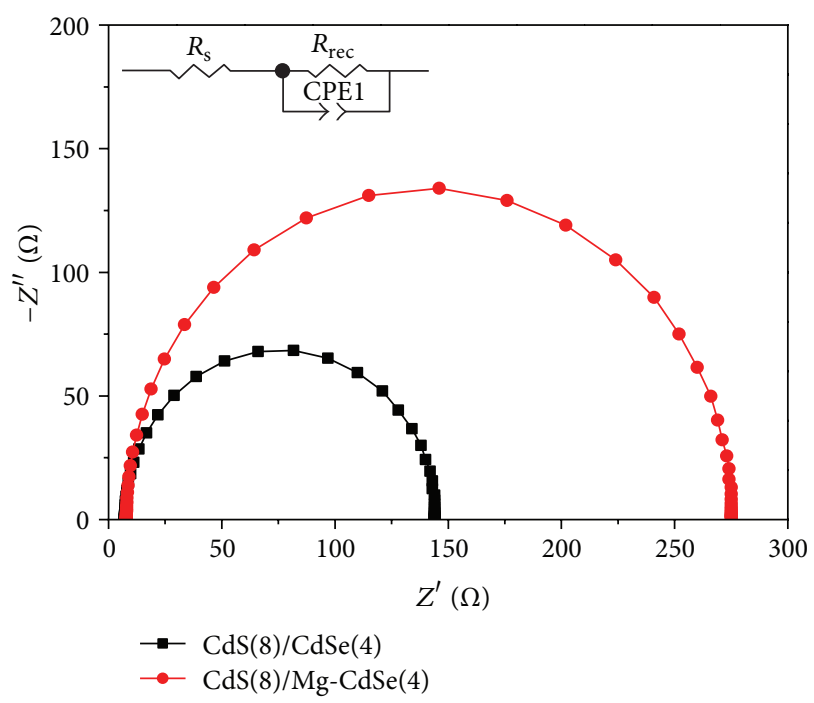

FIGURE 10: EIS of cells with the photoanode of CdS(8)/Mg-CdSe(4) and $\mathrm{CdS}(8) / \mathrm{CdSe}(4) . R_{s}$ is the series resistance of TCO electrodes, CPE1 is chemical capacitor of photoanode, and $\left(R_{\mathrm{rec}}=r_{\mathrm{rec}} L\right)$ is electron recombination resistance.

and the valence band of CdSe both have become higher after doping with $\mathrm{Mg}$. The stepwise structure yielded by level adjustment has enhanced the electron injection and the holerecovery and reduced the recombination between electrons and holes, that is, agreement with the improved photocurrent (Table 1). As a result, the conversion efficiency has been enhanced by doping CdSe with $\mathrm{Mg}$.

3.3.2. The Performance of Cells. The maximum value of IPCE has been improved after doping CdSe with Mg (Figure 9). In particular, the max value of IPCE has been improved from $37 \%$ to $42 \%$ in the wavelength of $350-475 \mathrm{~nm}$. This has been 
TABle 4: Parameters of EIS before and after doping.

\begin{tabular}{lccc}
\hline Sample number & $R_{s}(\Omega)$ & $R_{\text {rec }}(\Omega)$ & $\mathrm{CPE} 1(\mu \mathrm{F})$ \\
\hline $\mathrm{CdS}(8) / \mathrm{CdSe}(4)$ & 7.17 & 137.2 & 10.65 \\
$\mathrm{CdS}(8) / \mathrm{Mg}-\mathrm{CdSe}(4)$ & 7.92 & 267.4 & 14.54 \\
\hline
\end{tabular}

consistent with the improvement of preceding absorption spectrum and current density.

The electrochemical impedance spectroscopy (EIS) and the impedance fitting circuit diagram of photoanode and electrolyte are shown in Figure 10. The larger the $R_{\text {rec }}$, the smaller the electron concentration of photoanode and the recombination rate, and the greater the radius of the curves. So the recombination resistance has been increased by doping with $\mathrm{Mg}$ (Table 4).

Furthermore, the relationship of lifetime of electrons $(\tau)$ between chemical capacitor (CPE1) and electron recombination resistance $\left(R_{\text {rec }}\right)$ is summarized as

$$
\tau=\mathrm{CPE} 1 \cdot R_{\mathrm{rec}}
$$

The lifetime of electrons of CdS/Mg-CdSe system has been extended by doping CdSe with $\mathrm{Mg}$ compared with that of $\mathrm{CdS} / \mathrm{CdSe}$ system.

As the performance of cells is decided by several kinds of factors, although this new attempt did not produce a high energy conversion efficiency $(0.84 \%)$, we believe that we will get a high performance cell after overall optimization of cells.

\section{Conclusions}

Because of the doping with $\mathrm{Mg}$, the stepwise structure which has improved the electron injection and the hole-recovery has been yielded. And the absorbance has been enhanced. The lifetime of electrons has also been extended. Thus the performance of cells has been improved by doping CdSe with Mg effectively.

\section{Conflict of Interests}

The authors declare that there is no conflict of interests regarding the publication of this paper.

\section{Acknowledgments}

This work was partially supported by Key Project of Beijing Natural Science Foundation (3131001), Key Project of Natural Science Foundation of China (91233201 and 61376057), Key Project of Beijing Education Committee Science \& Technology Plan (KZ201211232040), State 863 Plan of MOST of China (2011AA050527), Beijing National Laboratory for Molecular Sciences (BNLMS2012-21), State Key Laboratory of Solid State Microstructures of Nanjing University (M27019), State Key Laboratory for New Ceramic and Fine Processing of Tsinghua University (KF1210), Key Laboratory for Renewable Energy and Gas Hydrate of Chinese Academy of Sciences (y207ka1001), Beijing Key Laboratory for Sensors of BISTU (KF20141077207 and KF20141077208), and Beijing
Key Laboratory for photoelectrical measurement of BISTU (GDKF2013005).

\section{References}

[1] J.-W. Lee, D.-Y. Son, T. K. Ahn et al., "Quantum-dot-sensitized solar cell with unprecedentedly high photocurrent," Scientific Reports, vol. 3, article 1050, 2013.

[2] W.-C. Kwak, K. T. Geun, W.-S. Chae, and Y.-M. Sung, "Tuning the energy bandgap of CdSe nanocrystals via $\mathrm{Mg}$ doping," Nanotechnology, vol. 18, no. 20, 2007.

[3] Y.-M. Sung, W.-C. Kwak, W. Kim, and T. G. Kim, "Enhanced ripening behavior of Mg-doped CdSe quantum dots," Journal of Materials Research, vol. 23, no. 7, pp. 1916-1921, 2008.

[4] L. Wonjoo, K. Woo-Chul, M. S. Ki et al., "Spectral broadening in quantum dots-sensitized photoelectrochemical solar cells based on CdSe and Mg-doped CdSe nanocrystals," Electrochemistry Communications, vol. 10, no. 11, pp. 1699-1702, 2008.

[5] Y.-C. Wang, M. Wang, X.-Y. Su, Z.-Y. Li, and W. Zhao, "Firstprinciples on the electron structure and optical properties of the Mg-doped CdSe system," Chinese Journal of Luminescence, vol. 31, no. 6, pp. 842-847, 2010.

[6] Y.-L. Lee and Y.-S. Lo, "Highly efficient quantum-dot-sensitized solar cell based on co-sensitization of CdS/CdSe," Advanced Functional Materials, vol. 19, no. 4, pp. 604-609, 2009.

[7] Z. Huang, X. Zou, and H. Zhou, "A strategy to achieve superior photocurrent by $\mathrm{Cu}$-doped quantum dot sensitized solar cells," Materials Letters, vol. 95, pp. 139-141, 2013.

[8] L. Li, X. Zou, H. Zhou, and G. Teng, "Cu-doped-CdS/Indoped-CdS cosensitized quantum dot solar cells," Journal of Nanomaterials, vol. 2014, Article ID 314386, 8 pages, 2014.

[9] X. Zou, S. He, G. Teng, and C. Zhao, "Performance study of CdS /Co-doped-CdSe quantum dot sensitized solar cells," Journal of Nanomaterials, vol. 2014, Article ID 818160, 6 pages, 2014. 

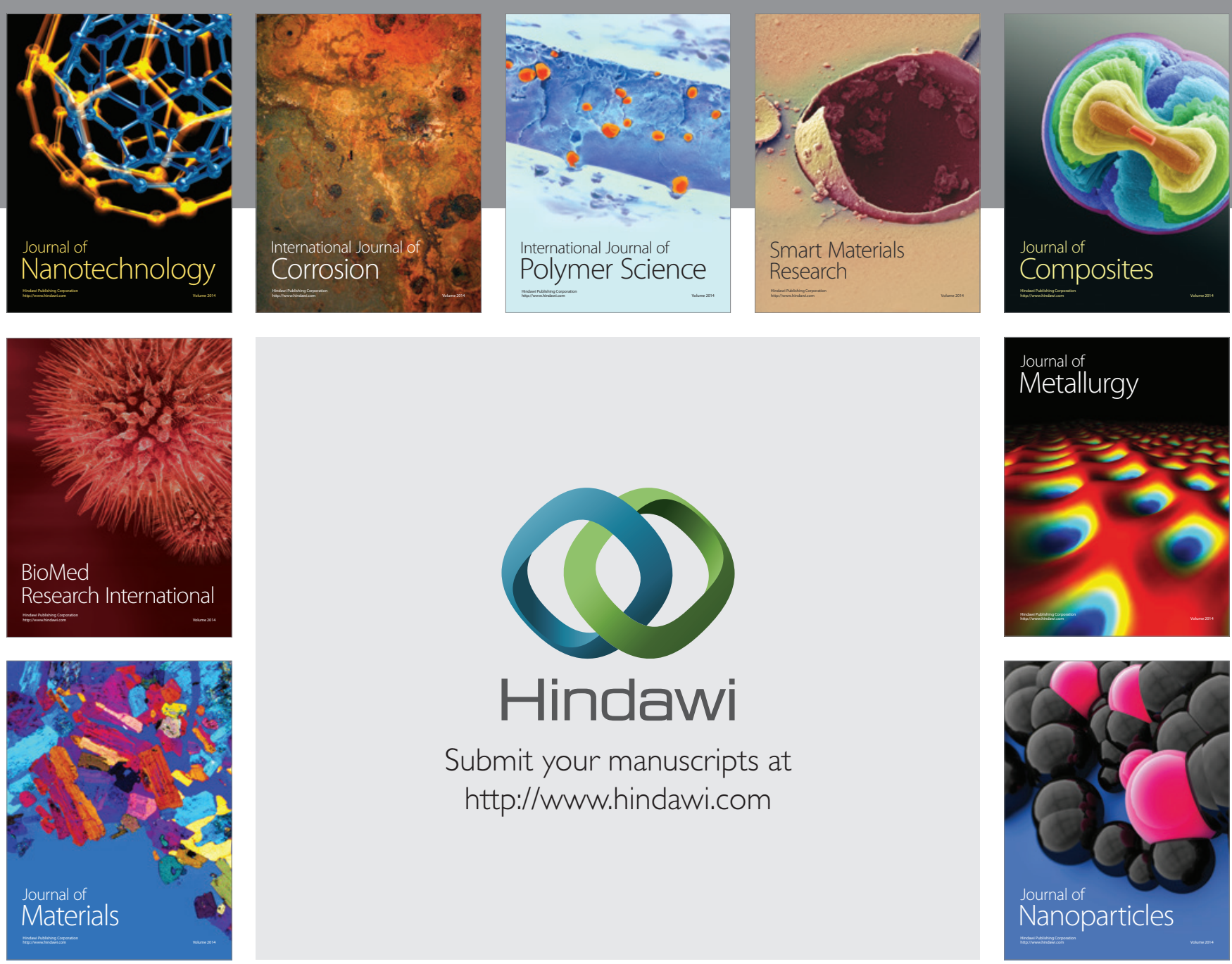

Submit your manuscripts at http://www.hindawi.com
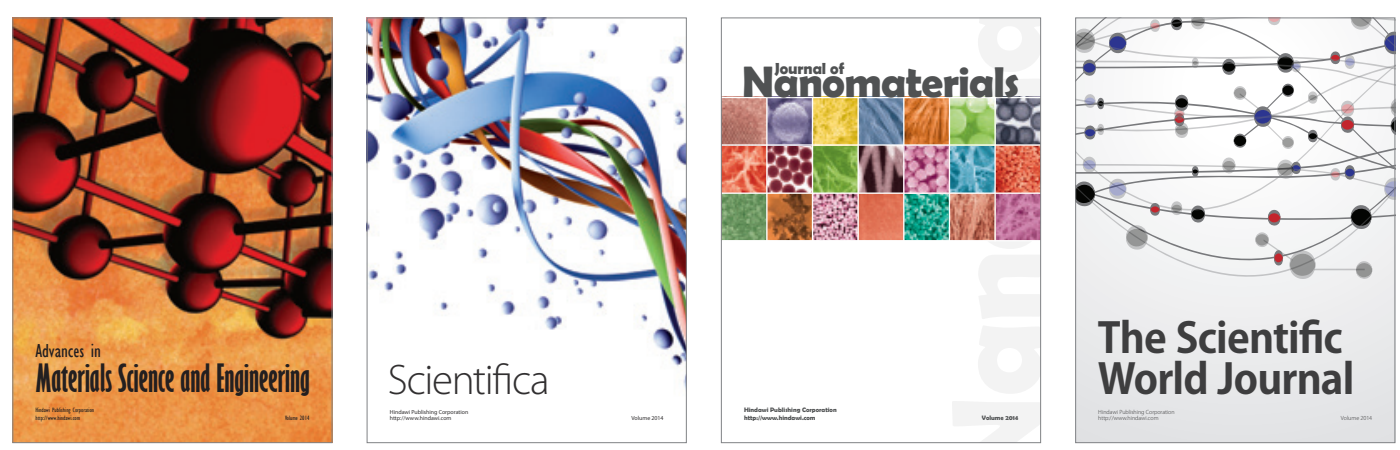

\section{The Scientific World Journal}
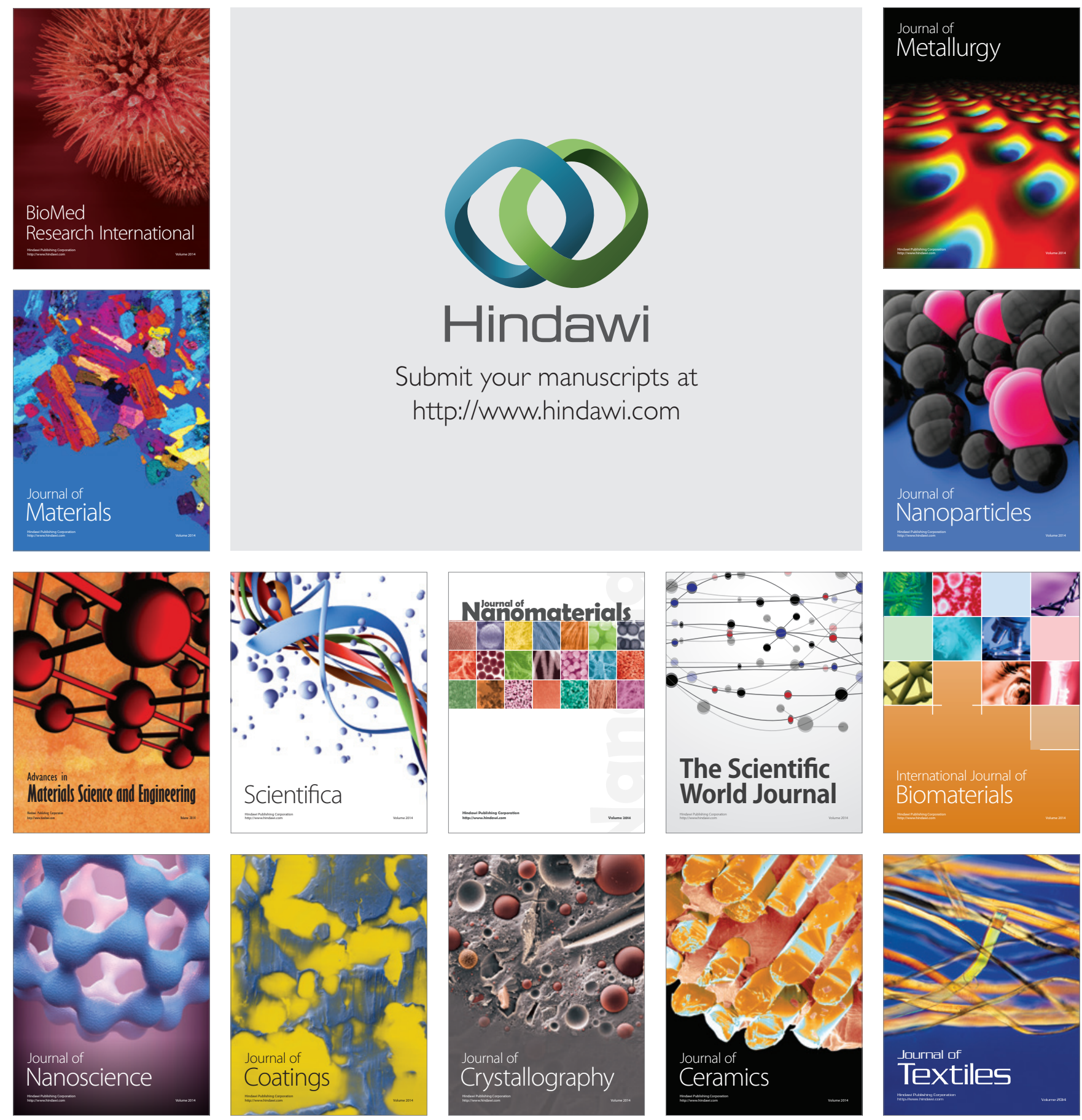